Www.jmscr.igmpublication.org

Index Copernicus Value: 79.54

ISSN (e)-2347-176x ISSN (p) 2455-0450

crossref DOI: https://dx.doi.org/10.18535/jmscr/v7i6.165

\title{
Quality of Life in Stroke Survivors in Central Kerala
}

\section{Authors \\ Dr PC Muralidharan ${ }^{1}$, Dr Bisha Babu², Dr G Chitra ${ }^{3}$, Dr. K Sreejith ${ }^{4}$, Dr S Abdul Gafoor 5}

${ }^{1}$ Asst Professor, Dept of Physical Medicine and Rehabilitation. Govt Medical College, Kottayam

${ }^{2}$ Asst Surgeon, Govt Medical College, Kottayam

${ }^{3}$ Asst Professor, Govt Medical College, Kottayam

${ }^{4}$ Associate Professor, Govt Medical College, Kottayam

${ }^{5}$ Professor \& Head Dept of Physical Medicine and Rehabilitation, Govt Medical College, Kottayam

\begin{abstract}
Background: Advances in acute care and rehabilitation in stroke has improved the functional outcome significantly. But the survivors have to cope up with alteration in their quality of life. An assessment of quality of life in stroke survivors validates successful rehabilitation.

Aim: To evaluate different domains of quality of life in post stroke patients attending rehabilitation unit of a tertiary care centre in Central Kerala.

Materials and Methods: The cross sectional study was conducted in the outpatient clinic of the Department of Physical Medicine \& Rehabilitation, Government Medical college Kottayam among the post-stroke patients of 3-6 months duration of illness.

Data was collected from the selected patients through structured questionnaire. The study tools included the socio-demographic and physical variables and the translated version of SSQOL (Stroke Specific Quality Of Life) questionnaire in local language.
\end{abstract}

Results: The quality of life in stroke survivors were reduced in the physical, social, psychosocial and functional domains.

Conclusion: The study calls for a structured rehabilitation program to improve the quality of life in stroke survivors.

Keywords: Stroke, Quality of Life, Central Kerala.

\section{Introduction}

Stroke, the third leading cause of disability ${ }^{1}$, causes a significant impact on the life of the survivor and the care giver. It is a non-traumatic brain injury that often leads to neurological deficits characterised by effects on motor, sensory, cognitive, language and equilibrium functions which subsequently leads to an alteration in the functional status of the survivor.
Many of these stroke survivors report a decline in the health related quality of life ${ }^{2}$.

About 15 million people suffer from stroke worldwide $^{3}$. About 5 million of them suffer from some forms of permanent disability. Age related prevalence reported with stroke was 250$300 / \mathrm{lakh}^{4}$. In India about 165000 incidence of stroke is reported every year ${ }^{5}$. Currently, the Western statistics show a decline in the incidence 
of stroke compared with India ${ }^{6}$ In spite of a decline in the global stroke mortality, incidence and disability rates, the burden of stroke continues to rise.

Stroke affects multiple domains of life which includes physical, mental, social and vocational. The tremendous advancements in the acute and the rehabilitation cares in stroke has led to significant improvement in the physical and mental well-being of the survivor. Their functional status and level of dependence for the activities of daily living influence their quality of life. The health care system has shown significant strides in coping with the physical, social and psychological sequel such that the assessment of the quality of life is an evaluator of the effectiveness of rehabilitation in the community ${ }^{7}$. The concept of quality of life encompasses physical, emotional and social well-being. WHO defines quality of life as an individual's perception of their position in life in context of their culture and value systems in which they live and in relation to their standards, goals, expectations and concerns ${ }^{8}$. It also indicates personal satisfaction ${ }^{9}$ influences and experiences $^{10}$ in matters regarding health and diseases, physical, mental and social interactions and well being ${ }^{11}$. This also measures the inter personal relations and health related indices and includes the various domains of physical (disease related), functional (activities of daily living), psychological (cognitive) and social (family and society) interactions ${ }^{12}$.

The burden of disease is measured in terms of Quality Adjusted Life Years (QALY) and Disability Adjusted Life Years (DALY) ${ }^{13}$. Several scales are available to assess the quality of lifeboth general and specific. SF 36, Euro QOL 5 Dimensional Questionnaire etc are some of the general scales. Stroke Specific Quality of Life Scale (SSQOL) and Stroke Impact Scale are stroke specific scales used for this purpose. Most of these are dependent on various factors of demographic pattern and ethnicity. The rehabilitation services available in the community have a significant role in determining the quality of life. The quality of life is a significant health care outcome relevant to the community and the existing health care system ${ }^{14}$. The outcome affects the patient, family and the society significantly.

On review of literature, stroke is attributed to cause significant reduction in the quality of life. ${ }^{15}$ The decline in functional status, age, depression, anxiety and fatigue have been associated with reduced quality of life post stroke while higher living standards and better education has positive influence $^{16}$. The Chinese, Swedish and French studies $^{17}$ have reported marked decline in the quality of life after stroke. Few studies have been conducted in India ${ }^{18,19}$, which also showed similar results. In Kerala very few such studies have been reported so far.

Post stroke, $37 \%$ patients show discrete changes, $16 \%$ show moderate changes and $32 \%$ show severe changes in the functional capacity ${ }^{20}$. Selfcare, mobility, upper extremity function, work and productivity are the domains where the survivors show significant decline ${ }^{21}$.

Though the several indices validate the physical and functional status attained by the stroke survivor, it barely represents the quality of life in the patient's perspective. SSQOL authenticates the patient's version of the quality of life bordering on different parameters in his perspective $^{22}$. This assessment is a pointer towards the efficiency of the existing treatment systems and its relevance. Since there is paucity of studies regarding the quality of life among the stroke survivors in Kerala, the present study was carried out.

\section{Materials and Methods}

A cross sectional descriptive study was done recruiting subjects from the outpatient clinic, Department of Physical Medicine \& Rehabilitation, Government Medical College, Kottayam. The patients who reported to the clinic from October 2018 to March 2019 (6months) were included in the study. Diagnosis of stroke was confirmed by clinical and/or radiological 
findings and perusal of the available records. The study was approved by the institutional ethical review board and informed consent was taken from all subjects. Sample size was calculated as 200 and it was calculated by using following formula:

$\mathrm{n}=\left(\mathrm{Z}^{2} * \mathrm{P}(1-\mathrm{P})\right) / \mathrm{e}^{2}$ where $\mathrm{Z}=$ value from standard normal distribution corresponding to desired confidence level ( $\mathrm{Z}=1.96$ for $95 \% \mathrm{CI}), \mathrm{P}$ is expected true proportion kept as $49.6 \%{ }^{20}$ the level of precision at $15 \%$.

Subjects were included if they had stroke, with a duration 3-6 months after the first episode of stroke. Subjects with concomitant neurological diseases, traumatic brain injury and tumor, severe cardiac, hepatic or renal diseases were excluded. Those patients with impaired comprehension and aphasia and with recurrent stroke were also excluded from the study. The subjects were excluded if they were unwilling to cooperate.

The data was collected using the Proforma to include various socio demographic and physical variables and the translated version of SSQOL scale in Malayalam. Demographic data included were age, gender, education, life style, side involved, type of lesion, site of lesion, family support, early rehabilitation, impairment (motor, speech and pain), depression, grip and gait. Data on risk factors were received from the old medical records and personal interview. Absence of risk factor was coded as 0 and presence was coded as 1. The different conditions considered were smoking, alcoholism, hypertension, diabetes mellitus, dyslipidemia and cardiac disease.

SSQOL $^{22}$ is a self-reported questionnaire specific for stroke, translated and validated in many countries. It has 49 items in 12 domains with three response sets in 5 point Likert format. This covers the domains of energy, family roles, language, mobility, mood, personality, self-care, social roles, thinking, upper extremity function, vision and work and productivity. The different responses are based on the amount of help required (no help to total help), amount of trouble experienced (unable to do to no trouble) and the degree of agreement with statements regarding functions (strongly agree to strongly disagree).

This covers each of the domains mentioned. The minimum score is 49 and the maximum is 245 . The higher the score, better will be the quality of life. A score of less than 60\% (147) is defined as low quality of life $^{20}$. Independent predictors of good overall HRQOL (Health Related Quality of Life) were the SSQOL score Odds Ratio 2.97; 95\% CI, 1.3, 7.1; $\mathrm{p}=0.01^{22}$.

Data analysis: Data analysis was performed by SPSS (version 17) for windows. Demographic and co-morbidities data was summarised as frequency and percentages. Descriptive statistics was performed to find out mean, range, minimum, maximum and standard deviation for the age and outcome variables (SSQOL). Microsoft excel and Word was used to generate graph and tables.

\section{Results}

The age of the subjects varied between 34 and 88 years with a mean of 60.03 and standard deviation of 9.89 years. The median and mode were found to be 60 years. The age distribution of the subjects in this study is summarised in the table below.

Table 1: Disribution of Age

\begin{tabular}{|l|c|c|}
\hline Age (Years) & Frequency & Percentage \\
\hline$<35$ & 3 & 1.5 \\
\hline $36-40$ & 5 & 2.5 \\
\hline $41-45$ & 6 & 3.0 \\
\hline $46-50$ & 27 & 13.5 \\
\hline $51-55$ & 25 & 12.5 \\
\hline $56-60$ & 36 & 18 \\
\hline $61-65$ & 37 & 18.5 \\
\hline $66-70$ & 36 & 18 \\
\hline$>70$ & 25 & 12.5 \\
\hline
\end{tabular}

8 subjects were below 40 years $(4 \%)$ and 98 subjects $(49 \%)$ above 60 years.41 of them $(20.5 \%)$ were below 50 years and $61(30.5 \%)$ between 50 and 60 years. 25 subjects (12.5\%) were above 70 years of age. There were 136 males $(68 \%)$ and 64 females (32\%).

In the present study, $81(40.5 \%)$ subjects had education below higher secondary level while 89 $(44.5 \%)$ subjects had higher secondary education. $29(14.5 \%)$ subjects had higher education. One person did not have any education. $78(39 \%)$ of 
our subjects were manual labourers, 19 (9.5\%) subjects were doing agriculture, $54(27 \%)$ subjects belonging to home making and 49 (24.5\%) subjects were belonging to 'others' (drivers, office work etc.). In the present study, 103 (51.5\%) had a sedentary life style and 97 (48.5\%) were physically active. In our study group, 112 (56\%) had right sided involvement and 88 (44\%) left side.

Graph 1: Risk factors in stroke

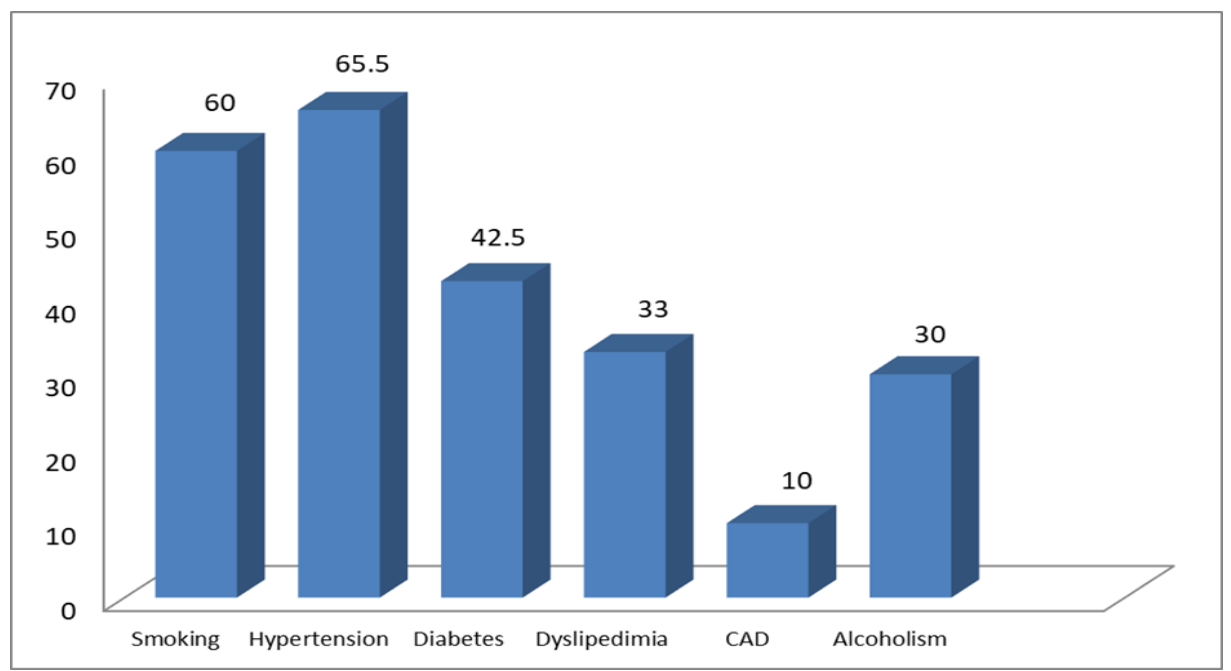

In our study, hypertension was found to be the most common risk factor associated with stroke $(65.5 \%)$, followed by smoking $(60 \%)$, diabetes (42.5\%), dyslipidaemia (33\%) alcoholism (30\%) and cardiac diseases (10\%).

173 subjects $(86.5 \%)$ had ischaemic stroke and 27 $(13.5 \%)$ haemorrhagic stroke. 185 subjects (92.5\%) had MCA stroke, 8(4\%) ACA and 7 (3.5\%) Posterior circulation stroke. Most of our subjects, 195 (97.5\%) had family support. In the present study, 138 (69\%) had undergone early rehabilitation in the first week while $62(31 \%)$ did not. All subjects had motor impairment, 85 (42.5\%) had speech impairment and 84 (42\%) had pain. 49 subjects $(24.5 \%)$ had treatment for depression. Vision, cognition and sensory are less effected.

Graph 2: Impairments

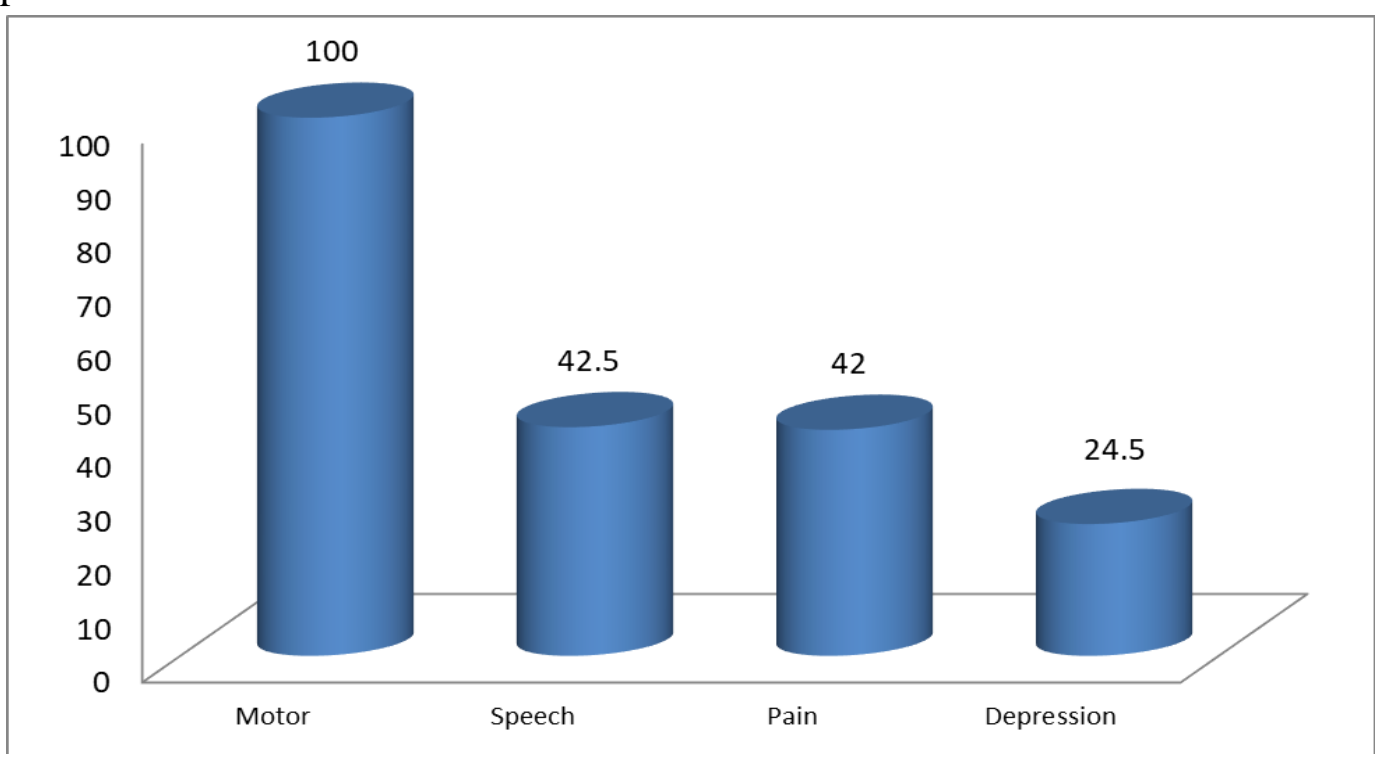


In the present study, 25(12.5\%) subjects had strong grip, $113(56.5 \%)$ subjects had moderate grip and $62(31 \%)$ subjects had weak grip.
$178(89 \%)$ subjects had independent gait and 22 $(11 \%)$ subjects had assisted gait.

Graph 3: Mean percentage of domains of QOL

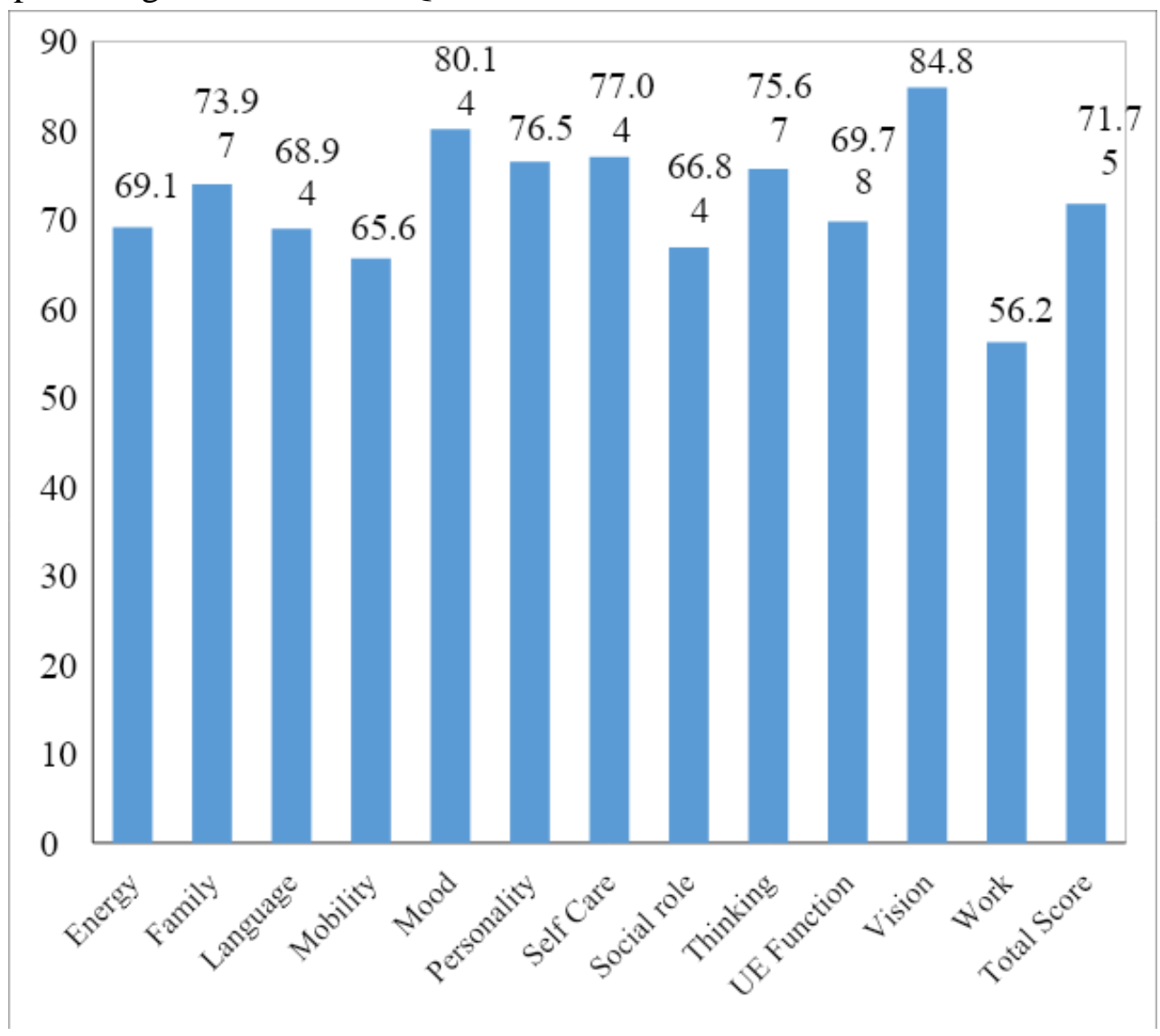

The mean total score was 175.88 with standard deviation of 26.10 and range, 100-231. Results showed that quality of life was low in 35 subjects $(17.5 \%)$.

Graph 2: QOL among stroke survivors

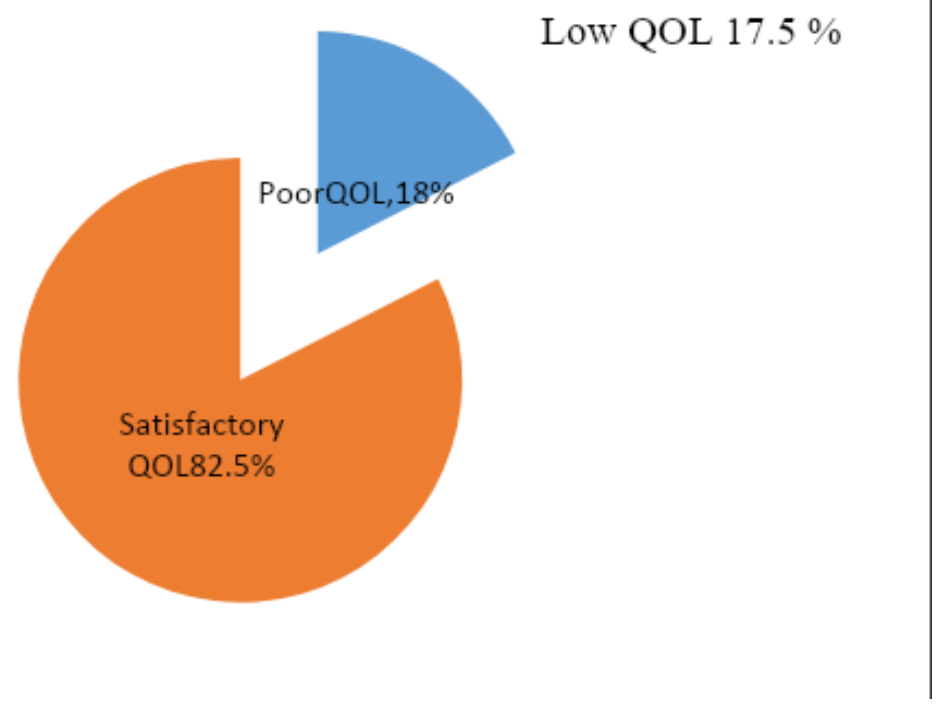




\section{Discussion}

In the present study, the mean age of the patients was 60.03 years. Of these, $68 \%$ were males. The age group varied from 34 to 88 years. $4 \%$ of the subjects were below 40 years and $49 \%$, above 60 years. Even the median age and mode were the same. This indicated that the present survey sample fit into normal distribution pattern.

In a study by Sylaja. et $\mathrm{al}^{23}$, the mean age of stroke in Kerala was 58.3 years with $67 \%$ males. $3.8 \%$ constitute patients below 40 years. These results were comparable to our study. But $67 \%$ of their subjects were 60 years or more. In the study by Sridharan.et $\mathrm{al}^{24}, 77 \%$ subjects were above 60 years while $3.8 \%$ were below 40 years. In these two studies, the sample size was large $(n=2066$, $\mathrm{n}=541$ respectively) compared to our study $(n=200)$ and this could be the reason for the variation. Chandran P.et $\mathrm{al}^{25}(\mathrm{n}=47)$, in their study reported a mean age of 70.58 , of which $67.5 \%$ were males. Rajan B.et al ${ }^{18}$ reported their mean age to be 61.33 years, again comparable to our results. The mean age for stroke onset is 63 years in India, while it is higher in the West, 68 years in the US and 71 years in Italy ${ }^{26}$. In the study by Wade. et $\mathrm{al}^{27}$ the mean age was 72.4 years of which $2 \%$ was below 45 years and $79 \%$ above 65 years. This could be explained by ethnicity.

In the present study, only one person was illiterate. Rajan B.et al and Rinu Susan Raju et al reported significant number of illiterates among their subjects ${ }^{18} 19$. Level of education shows an inverse relationship with stroke incidence ${ }^{28}$ and higher levels of education is associated with higher quality of life among stroke survivors ${ }^{29}$. Because of higher literacy in Kerala and better standards of living, the patient and the care givers are amenable to life style modifications, better adherence to treatment and better coping.

Majority of our subjects were manual laborers. $51.5 \%$ of our subjects followed a sedentary lifestyle. The occupation of an individual influences the socioeconomic status and physical activity of the individual modifying the risk factors of stroke. The physical activity may reduce blood pressure, diabetic status and body weight and improve circulation ${ }^{31}$.

In our study, 56\% had right sided weakness while $44 \%$ had left sided weakness. Wade. et $\mathrm{al}^{27}$ reported $46 \%$ of their subjects with right sided weakness and $40 \%$ left sided weakness. In the study by Rajan B. et $\mathrm{al}^{18} 56 \%$ had right sided weakness, 39\% had left sided weakness and 5\% bilateral involvement. In our study there were no bilateral cases. The quality of life in right sided hemiplegics was reported to be better except in the domain of communication. Left hemiplegics also reported decline in communication skills and this suggested that this ability depended on other factors like motor and cognitive skills, indicating a weak association between quality of life and laterality of lesion ${ }^{31}$.

In majority of the studies including ours (86.5\%), ischemic strokes constituted the vast majority .There has been reports of reduction in haemorrhagic stroke annually by $1.7 \%$ and a rise in the ischemic stroke incidence by $8.7 \%{ }^{33}$. This could be attributed to the advancements in treatment of risk factors, Western style diets and life styles .The territory of involvement in our subjects showed a similar pattern when compared to the studies worldwide ${ }^{32,34}$.

The various studies have reported hypertension to be the most frequent comorbidity varying from $45.5 \%$ in Lausanne Stroke Registry ${ }^{34}$ to $83.2 \%$ in Sridharan et $\mathrm{al}^{24}$. The range for diabetes varied from $12.6 \%$ to $50 \%$. In studies elsewhere, cardiac diseases, especially atrial fibrillation is considered to be a high risk for stroke. Dyslipidaemia is reported to have a significant influence on stroke. High cholesterol levels are associated with ischemic strokes while there is an inverse relation with haemorrhagic stroke. These risk factors are quite common probably due to socio- economic reasons, poor awareness and lack of infrastructure. In India, these modifiable risk factors are inadequately controlled and hence account for higher stroke prevalence than the $\mathrm{West}^{35}$.

In our study, $60 \%$ of our subjects were smokers and $30 \%$ used to consume alcohol. Definite dose- 
response relationships and associations have been reported between smoking and ischemic stroke. Cessation of smoking or reduction in smoking reduces the risk ${ }^{36}$. A $\mathrm{J}$ shaped association between alcohol consumption and total and ischemic stroke has been attributed ${ }^{37}$. Heavy drinking increased stroke risk while a lower dose had no such effects. Family status and support is an integral component of rehabilitation especially in Indian scenario. Most of our subjects were married and well supported by family (97.5\%). $2.5 \%$ subjects who did not receive any family support were either single or divorced. The interaction of the patient with the family, support by members and care given by them influences the functional status. In India where joint family system was in vogue it had a positive influence in stroke rehabilitation $^{19}$.

$69 \%$ of our patients underwent early rehabilitation while in the acute phase of treatment which influenced recovery. The rest of the patients were not referred for early rehabilitation or did not attend this phase of care for some reason. Early rehabilitation is found to have influence on the outcome of stroke ${ }^{38}$.

The SSQOL measures the overall quality of life in a post stroke patient as perceived by him. Only a limited number of studies are available with regard to Quality of Life and our study attempted to gauge the performance ability, level of dependency, psychological and social effects, satisfaction and energy of the individual patient as experienced by him or her. In our study, the score was below $60 \%$ in $17.5 \%$ of our subjects indicating a low quality of life in them at 3-6 months post stroke.

In general we found that the quality of life was satisfactory in $82.5 \%$ of the subjects. We explored the QOL of the stroke survivor in terms of behaviour, cognition, functional mobility, language, upper extremity function, personality, social relationships etc. all covered in the 12 domains of the questionnaire. Higher scores indicated better QOL. It was found that the most affected domain was Work and productivity
(56.2). The domain of mobility was the next affected (65.60), followed by Social roles (66.84) and language (68.94). The least effected ones were Vision (84.80), Self- care (77.04) and personality (76.50).

Review of literature reports a reduction in the health related quality of life in stroke survivors ${ }^{2}$. Our mean score was 175.88. $17.5 \%$ of our subjects had scores below 147, indicating a low quality of life. A majority of our subjects showed a satisfactory QOL, though the scores were suboptimal. Studies in Pakistan reported mean scores of 164.18 (SD 32.3) while in Brazil it was139.9 (SD 38.4) and in Nigeria, it was 156.7 (SD 41.6) ${ }^{39}$. This difference could be due to good social support, better socioeconomic status, improved literacy and higher education in our area.

In the study by Ketaki. et $\mathrm{al}^{21}$, the four domains which were most affected were work and productivity, self-care, mobility and upper extremity functions. In a Turkish study ${ }^{21}$, upper extremity function was the most effected while Malawi $^{16}$ reported Self-care as the domain maximally affected. In a study in geriatric patients, the most affected domain was work and productivity ${ }^{40}$. In the original study by Williams et $\mathrm{al}^{22}$, mobility (66\%), energy (65\%), Upper extremity (62\%), work and productivity $(61 \%)$, mood $(45 \%)$, self-care $(41 \%)$, social roles $(39 \%)$, Family roles(38\%), vision(38\%), thinking (37\%) and personality $(21 \%)$ were involved in that order. All our patients had motor impairment and a major number of patients had speech involvement. Even though treatment was initiated early, they were in the process of recovery and rehabilitation. Hence their level of dependency and performance is low, giving a reduced total score.

Majority of our patients had good family support which might have influenced the QOL in all domains $^{29}$. The age group affected more in our study was low compared to the West and many studies elsewhere. This difference in age group may be responsible for the variation in the domains affected. The level of education, better 
living standards, more awareness and standard rehabilitation practices may also account for this. The availability of early rehabilitation facilities might also have influenced the domains affected, especially in the upper extremity functions which is less effected in our studies compared to others. The subjects were recruited from clinical settings and hence might be under sampled. Since the subjects were selected from a rehabilitation unit it might not reflect the community as a whole. None of the outcome measures describe the dimensions of recovery and disability and predict the actual outcome after the stroke episode. No clear picture of the physical, mental and social status of the person has been provided. Rural -urban variations and socioeconomic consideration were also not taken into account.

There is scope for further studies to facilitate the development of structured rehabilitation strategies. Further studies can be undertaken to assess the difference in QOL between subjects who received early rehabilitation and those who did not. Studies can also be undertaken in other demographic variables such as age and gender to assess the QOL.

\section{Conclusion}

The quality of life in stroke survivors in Central Kerala is found to be suboptimal. Work and productivity, mobility, language and social roles are mostly effected. This calls for the development of a structured rehabilitation pathway whereby motor, speech, social and vocation can be addressed in a more productive manner.

\section{References}

1. Fergin, Bo Norrving, George A Mensa. Global burden of stroke, Circulation Research, February 3, 2017;439.

2. King R.B.Quality of life after stroke,Stroke.1996 Sep;27(9):1467-72

3. Stroke Statistics|Internet Stroke Center [Internet].cited 2018 Jun20, 10 AM] Available from:http://www.strokecenter.org/patients/ about-stroke-statistics

4. T K Banergy. Epidemiology of stroke in India, Neurology Asia 11:1-4, January 2006.

5. Vasantha M Padma, Rohit Bhatia.et al. A call for neurologists to take up stroke interventions, Ann Indian Acad Neurol.2016 Oct- Dec;19(4):429-432

6. William G Akanksha et al. Clinical Features, Risk Factors, and Short- term outcome of Ischemic Stroke in Patients with Atrial Fibrillation: Data from a Population- based Study, Ann Indian Acad Neurol.2017 July-Sep;20(3):289-293

7. JA Opara and K Jaracz. Quality of life of post-stroke patients and their caregivers, $\mathrm{J}$ Med Life.2010 Aug15;3(3):216-220 [Published online2010 Aug 25]

8. WHO QOL group, Development of the World Health Organization WHOQOLBREF quality of life assessment; Psychol Med. 1998: 28: 551-558.

9. Hornquist JO. The Concept of quality of life. Scand J Soc Med. 1982;10:57-61.

10. Stroke Unit Treatment Improves Long Term Quality of Life|Stroke [Internet]. Available from: http;//stroke.ahajournals.org/content/29/5/ 895

11. Assessment of quality of life in clinical trials of cardiovascular therapies.-PubmedNCBI[Internet] [cited 2018 June21, 6.00 $\mathrm{PM}]$

12. Quality of life: what is it? How should it be measured?- Pubmed-NCBI[ Internet] cited2018 june21,8.15 PM

13. Mei- Chiun Tseng and Huey Suan Lin. Health Related Quality of Life after Stroke: Review of Literature and Implication for future research, Acta Neurologica Taiwanica, Vol 16 No1 March 2007;16:7-12.

14. Kamel A, Ghani AA, Zaiton MA, ElMotayam AS, El-Fattah DA. Health 
related quality of life in stroke survivors measured by the Stroke Impact Scale. Egypt J Neurol Psychiatry Neurosurg. 2010;47:267-74.

15. Dhamoon MS et al.Quality of life declines after first ischemic stroke. The Northern Manhattan Study. Neurology 2010 July 27;75(4):328-334

16. T Heikinheimo and D Chimbayo. Quality of life after first ever stroke: An interview based study from Blantyre, Malawi. Malawi Med J.Jun;27(2):50-54

17. K. Laurent et al. Assessment of quality of life in stroke patients with hemiplegia. Annals of Physical and Rehabilitation medicine 54 (2011)376-390

18. Rajan B et al. Assessment of quality of life among stroke survivors: a longitudinal study. International Journal of Community Medicine and Public Health2019 Mar;6(30:1316-1323

http://www.ijcmph.com

19. Rinu susan Raju et al. Psychosocial Problems, Quality of Life, and Functional Independence Among Indian Stroke Survivors. Stroke.2010;41:2932-2937

20. Edja Solange Souza Rangel; Angélica Gonçalves Silva Belasco; Solange Diccini. Quality of life of patients with stroke rehabilitation, Available from: http:// www. scielo.br/scie lo.php?pid=S0103$21002013000200 \quad 016 \& \quad$ script $=$ sci_arttext\&tlng=en

21. Ketaki Vijai Mandke and Suvarna Shyam Ganvir. Quality of Life in Patients with Stroke, volume 3 Issue ! October 2017.

22. Williams LS, Weinberger M, Harris LE, Clark DO, Biller J. Development of a stroke-specific quality of life scale. Stroke. 1999;30(7):1362-9.

23. Sylaja PN. et al. Ischemic Stroke Profile, Risk Factors, and Outcomes in India: The Indo-US Collaborative Stroke Project Stroke. 18 Jan;49(1):219-222. doi:
10.1161/STROKEAHA.117.018700. Epub 2017 Nov 22.

24. Sridharan SE, Unnikrishnan JP, Sukumaran S, Sylaja PN, Nayak SD, Sarma PS, et al. Incidence, types, risk factors, and outcome of stroke in developing country: The Trivandrum Stroke Registry. Stroke. 2009;40:12128.https://doi.org/10.1 161/ STROKEAHA. 108.531293

25. Chandran P et.al. Assessment of quality of life of stroke survivors in a rural area of North Kerala, India. Int J Community Med Public Health.2017 Mar:4(3):841-846

26. Wasay M, Khatri IA, Kaul S. Stroke in south Asian countries. Nat Rev Neurol; 10: 135-43

27. Derick T Wade, Richard Langton Hewer .Stroke: AssociationsWith Age, Sex, and Side of Weakness. Arch Phys Med Rehabil Vol 67, Aug 1986 540-545

28. Cabral NL et al. Education Level Explains Differences In stroke Incidence among City Districts in Joinville Brazil: A Three Year Population Based Study. Neuroepidemiology 2011;36:258-264

29. Dayapoglu N, Tan M. Quality of life in stroke patients. Neurol India [serial online] 2010 [cited 2018 Jan 19];58:697-701.

30. Manson JE ,et al A prospective study of maturity-onset diabetes mellitus and risk of coronary heart diseases and stroke in women. Arch. Intern Med.1991Jun; 151(6):1141-7

31. Haan RJ .et al .Quality of life After Stroke, Impact of Stroke Type and Lesion Location.Stroke.1995;26:402-408

32. Sharif F. et al. Prevalence of risk factors associated with stroke. Pak Heart J;52(01): 91-95

33. Amelia K Boehme, Charles Esenwa, Mitchell S.V. Elkind. Stroke Risk Factors, Genetics and Prevention. Circ Res.2017 Feb 3;120(3):472-498 
34. Bigousslavsky $\mathbf{J}$ et al. The Lausanne Stroke Registry: analysis of 1000 consecutive patients with first stroke. Stroke 1988 Sep;19(9);1083-92

35. Tapas Kumar Banerjee and Shyamal Kumar Das. Fifty years of stroke researches in India. Ann Indian Acad Neurol.2016 Jan- Mar;1991):1-8

36. Markidan $\mathbf{J}$ et al. Smoking and Risk of Ischemic Stroke in Young Men. Stroke. 2018;49:1276-127

37. Christensen. et al.Alcohol Intake and Risk of Ischemic and Haemorrhagic Stroke: Results from a Mendelian Randomisation Study. J Stroke 2018 May;20(2):218-227

38. Matsui et al. An exploration of the association between very early rehabilitation and outcome for the patients with acute ischemic stroke in Japan: a nationwide retrospective cohort survey. BMC Health Services Research 2010 10:213 https://doi.org/10.1186/14726963-10-213

39. Wardah Khalid et al. Quality of life in stroke in Pakistan. BMC Neurology, 2016, Vol 16, Page 1.

40. Gunaydin R. et al. Determinants of quality of life (QOL) in elderly stroke patients: A short term follow up study.Arch Gerontol Geriatr.2011July- Aug;53(1):19-23. 